\title{
Development and characterization of novel SSR markers in Siniperca kneri Garman
}

\author{
M. Yang ${ }^{1,2 *}$, H.Z. Zheng ${ }^{1,2 *}$, X.-F. Liang ${ }^{1,2}$, C.X. Tian ${ }^{1,2}$, Y.Q. Dou ${ }^{1,2}$, \\ K.C. Zhu ${ }^{1,2}$ and Y.C. Yuan ${ }^{1,2}$ \\ ${ }^{1}$ Key Lab of Freshwater Animal Breeding, College of Fisheries, \\ Huazhong Agricultural University, Ministry of Agriculture, \\ Wuhan, Hubei, China \\ ${ }^{2}$ Hubei Collaborative Innovation Center for Freshwater Aquaculture, \\ Wuhan, Hubei, China \\ *These authors contributed equally to this study. \\ Corresponding author: X.F. Liang \\ E-mail: xufang_liang@hotmail.com \\ Genet. Mol. Res. 13 (3): 7593-7606 (2014) \\ Received June 12, 2013 \\ Accepted September 25, 2013 \\ Published March 24, 2014 \\ DOI http://dx.doi.org/10.4238/2014.March.24.18
}

\begin{abstract}
In this study, 37 transcriptome-derived simple sequence repeat (SSR) markers and 18 genomic SSR markers were developed and characterized in the Chinese perch, Siniperca kneri Garman. The average allele number per locus was 5.1 (range: 2-8) for transcriptome-derived SSRs and 3.8 (range: 2-5) for genomic SSRs. The average observed and expected heterozygosities were 0.666 (range: 0.000-1.000) and 0.692 (range: $0.230-0.857$ ) for transcriptome-derived SSRs, respectively. These values were 0.380 (range: 0.000-1.000) and 0.527 (range: 0.201-0.799) for genomic SSRs, respectively. The average polymorphic information content was 0.638 (range: 0.215-0.824) for transcriptome-derived SSRs and 0.477 (range: $0.183-0.752$ ) for genomic SSRs. Seven of these loci exhibited departure from Hardy-Weinberg equilibrium after sequential Bonferroni's correction for multiple tests, and no significant deviation was observed for the linkage disequilibrium. These developed and characterized markers are anticipated to be useful for studies on population genetics,
\end{abstract}


conservation genetics, and the fishery management of this species.

Key words: Siniperca kneri Garman; Genome; Simple sequence repeat; Transcriptome

\section{INTRODUCTION}

The Chinese perch, Siniperca kneri Garman, is an endemic species to East Asia, and is primarily distributed in the Yangtze River drainage system of China. This fish species is one of the most economically and geographically important species in the genus Siniperca (Zhou et al., 1988). Unfortunately, the wild stock is declining because of excessive exploitation and environmental pollution (Liang, 1996). Therefore, the rational use of natural resource is urgently required to maintain, and possibly enhance, the quality of brood stock.

SSR markers are used extensively in molecular ecology and conservation genetics, as well as in stock assignment and assessments of genetic diversity for commercial fish (Perez et al., 1999; Hansen et al., 2001a,b). SSR markers have been developed for some Siniperca species, such as Siniperca chuatsi (Kuang et al., 2009; Liu et al., 2011) and Siniperca scherzeri Steindachne (Qu et al., 2012; Yang et al., 2012). However, polymorphic SSRs have not been developed for $S$. kneri because of a lack of sequence information. Thus, sequence information, particularly transcriptomes, of closely related species could be used to reveal the polymorphisms of $S$. kneri.

Transcriptome sequencing, which is the DNA sequencing of the mRNA pool of a given tissue, has allowed sequencing efforts to focus on the protein-coding portion of the genome. As a result, this technique has enabled large numbers of molecular markers to be developed for nonmodel organisms, both quickly and at relatively low cost (Bouck and Vision, 2007). Recently, the transcriptome assemblies of the $\mathrm{F}_{1}$ interspecies hybrids between $S$. chuatsi $\left({ }_{(}\right)$and $S$. scherzeri Steindachne $\left({ }^{\Uparrow}\right)$ were generated using Illumina paired-end sequencing technology (He et al., 2013). In this study, we developed 37 SSR markers from this previously developed transcriptome database. In addition, a further 18 genomic SSRs were also derived from SSR-enriched genomic libraries of $S$. kneri. This study is the first to report the successful use of transcriptome sequences and repeat enriched genomic libraries for SSR marker development in S. kneri. These SSR primers are anticipated to be useful for studies on population genetics, conservation genetics, fishery management, and for the construction of genetic linkage maps of S. kneri.

\section{MATERIAL AND METHODS}

\section{Collection and DNA extraction}

Thirty-two wild $S$. kneri individuals were collected from 4 sites (Guangzhou: $23^{\circ} 04^{\prime} \mathrm{N} 113^{\circ} 28^{\prime} \mathrm{E}$, Nanchang: $23^{\circ} 04^{\prime} \mathrm{N} 113^{\circ} 28^{\prime} \mathrm{E}$, Wuhan: $30^{\circ} 35^{\prime} \mathrm{N} 114^{\circ} 17^{\prime} \mathrm{E}$, Changsha $28^{\circ} 13^{\prime} \mathrm{N} 112^{\circ} 56^{\prime} \mathrm{E}$ ), and 8 individuals from each site. The distance among them were: $\mathrm{Wu}-$ han to Changsha, $290.8 \mathrm{~km}$; Wuhan to Nanchang, $262 \mathrm{~km}$; Changsha to Nanchang, 293 km; Wuhan to Guangzhou, $856.9 \mathrm{~km}$; Changsha to Guangzhou, $563 \mathrm{~km}$; Nanchang to Guangzhou, $705 \mathrm{~km}$. Total genomic DNA was extracted from fin clips using the TIANamp Genomic DNA Kit (Tiangen, Beijing, China), according to manufacturer protocols. The DNA was adjusted to $100 \mathrm{ng} / \mu \mathrm{L}$ and then stored at $-20^{\circ} \mathrm{C}$ until use. 


\section{SSR mining from transcriptome}

The transcriptome assemblies of the $\mathrm{F}_{1}$ interspecies hybrids between $S$. chuatsi (q) and $S$. scherzeri (ठ) were generated using the Illumina paired-end sequencing technology. Potential SSR markers were detected among the unigenes of this transcriptome using the BatchPrimer3v1.0 software (You et al., 2008). The parameters were adjusted for the identification of perfect di-, tri-, tetra-, penta-, and hexa-nucleotide motifs, with a minimum of 6,5 , 3,3 , and 3 repeats, respectively. Mononucleotide repeats were excluded, because it was difficult to distinguish genuine mononucleotide repeats from polyadenylation products and single nucleotide stretch errors generated by sequencing. The primers for these SSR loci were designed using NCBI/Primer-BLAST (http://www.Ncbi.nlm.Nih.gov/tools/primer-blast/index. cgi?LINKLOC=BlastHome).

\section{Isolation of genomic SSR}

SSRs were isolated using a hybridization-based capture methodology, following the protocol described by Billotte et al. (1999). Briefly, the extracted genomic DNA was digested with the restriction enzyme MseI (BioLabs). DNA fragments of 300-1000 bp were selected using electrophoresis on agarose gel, and the excised gel was purified using a PBZ0202-1 DNA purification kit (Sangon Biotech, Shanghai, China). Specific adapters (5'-GACGATGAGTCCTGAG-3' and 5'-TACTCAGGACTCAT-3') were then ligated to the digested DNA. Approximately amplified DNA fragments were hybridized with 5'-biotinlabeled oligonucleotides $(\mathrm{GA})_{20}$ and $(\mathrm{CCT})_{15}$. Then, streptavidin magnetic beads (Sangon Biotech) were used to capture the target fragments. The captured DNA fragments were eluted from the beads-probe DNA mixture, by treating it with T-Elution buffer at $95^{\circ} \mathrm{C}$ for $5 \mathrm{~min}$. The enriched DNAs were cloned into the pGEM-T plasmid vector (Promega Beijing Biotech, Beijing, China), and were transformed into competent Escherichia coli strain DH-5 $\alpha$ (Promega Beijing Biotech). White colonies were randomly selected from the primary transformation plates, and the isolated Plasmid DNA was sequenced by an ABI 3730 Genetic Analyzer (Applied Biosystems). SSR clones were identified by screening with the SSRHUNTER software (Li and Wan, 2005). Then, sequences containing SSRs with 5 or more repeats were selected for primer design using the PRIMER PREMIER 5.0 program (PREMIER Biosoft International, USA).

\section{PCR amplification and genotyping}

PCRs were performed in a final volume of $25 \mu \mathrm{L}$ containing 50 ng genomic DNA, $2.5 \mu \mathrm{L} 10 \mathrm{X}$ PCR buffer, $1.0-3.0 \mathrm{mM} \mathrm{MgCl}, 0.4 \mu \mathrm{M}$ of each primer, $50 \mu \mathrm{M}$ of each dNTP, and 1.0 U EasyTaq ${ }^{\mathrm{TM}}$ DNA polymerase (Transgen, Beijing, China). PCR amplifications were conducted under the following conditions: 5 min at $94^{\circ} \mathrm{C}$, followed by 35 cycles of 30 $\mathrm{s}$ at $94^{\circ} \mathrm{C}, 45 \mathrm{~s}$ at a primer-specific annealing temperature (Table 1 ), 1 min at $72^{\circ} \mathrm{C}$, with a final extension step of $10 \mathrm{~min}$ at $72^{\circ} \mathrm{C}$. The PCR products were separated on a sequencing gel containing $8 \%$ polyacrylamide, and were visualized by silver staining. The denatured pBR322 DNA/MspI molecular weight marker (Tiangen, Beijing, China) was used as size standard to identify alleles. 
Table 1. Characterization of the polymorphic microsatellite markers in a sample of 32 Siniperca kneri Garman individuals including locus name, repeat motif, primer sequences, allele size range, annealing temperature (Ta), locus type, number of observed alleles $\left(N_{\mathrm{A}}\right)$, observed $\left(H_{\mathrm{O}}\right)$ and expected heterozygosities $\left(H_{\mathrm{E}}\right)$, polymorphism information contect (PIC), chi-square tests for Hardy-Weinberg equilibrium (HWE) after Bonferroni's correction (adjusted $\mathrm{P}$ value $=0.0009$ ) and Genbank accession number.

\begin{tabular}{|c|c|c|c|c|c|c|c|c|c|c|c|}
\hline Locus name & Repeat motif & Primer sequence $\left(5^{\prime}-3^{\prime}\right)$ & $\begin{array}{l}\text { Size range } \\
\text { (bp) }\end{array}$ & $\begin{array}{c}\mathrm{Ta} \\
\left({ }^{\circ} \mathrm{C}\right)\end{array}$ & $\begin{array}{l}\text { Locus } \\
\text { type }\end{array}$ & $N_{\mathrm{A}}$ & $H_{\mathrm{O}}$ & $H_{\mathrm{E}}$ & PIC & $\mathrm{P}_{\mathrm{HWE}}$ & $\begin{array}{c}\text { GenBank } \\
\text { accession } \\
\text { No. }\end{array}$ \\
\hline \multicolumn{12}{|c|}{ Transcriptome-derived SSR } \\
\hline SK472 & $\begin{array}{c}(\mathrm{TG})_{6} \mathrm{~N} \\
(\mathrm{GTGGA})\end{array}$ & $\begin{array}{l}\text { F: GTATTTGGCAGGCTTTTAG } \\
\text { R: TAGACTCGTCTCCCTGACA }\end{array}$ & $268-373$ & 57 & I & 4 & 0.781 & 0.734 & 0.674 & 0.090 & JX503195 \\
\hline SK473 & $(\mathrm{CA})_{28}$ & $\begin{array}{l}\text { F: TTCATCCTGTCTCACCGC } \\
\text { R: CACTGCCACAGCTAGGATCA }\end{array}$ & $232-289$ & 55 & $\mathrm{P}$ & 5 & 1.000 & 0.796 & 0.749 & 0.060 & JX503194 \\
\hline SK483 & $\begin{array}{c}(\mathrm{AC})_{8} \mathrm{~N} \\
(\mathrm{AC})_{6}\end{array}$ & $\begin{array}{l}\text { F: AGGTTGGATTTTGGGTCAAT } \\
\text { R: AAGGCACTTCGGCTAATG }\end{array}$ & $221-309$ & 55 & I & 5 & 0.719 & 0.810 & 0.765 & 0.170 & JX503184 \\
\hline SK490 & $\begin{array}{c}(\mathrm{GT})_{25} \mathrm{~N}(\mathrm{GAA})_{7} \\
\mathrm{~N}(\mathrm{GAT})_{4}\end{array}$ & $\begin{array}{l}\text { F: CAGCAGGAATTGGGATGAAA } \\
\text { R: CAGATGCGGCCAATACAAGA }\end{array}$ & $247-306$ & 55 & I & 7 & 0.813 & 0.830 & 0.794 & 0.553 & JX503177 \\
\hline SK491 & & $\begin{array}{l}\text { F: GCTCTTGCTCCCTTTTACTT } \\
\text { R: TAGCCGTGGAGATGGGAATA }\end{array}$ & $245-266$ & 55 & $\mathrm{P}$ & 5 & 1.000 & 0.770 & 0.720 & $0.000^{*}$ & JX503176 \\
\hline SK492 & $\begin{array}{l}(\mathrm{GT})_{6} \mathrm{~N} \\
(\mathrm{AC})_{9}\end{array}$ & $\begin{array}{l}\text { F: GT } \\
\text { R:AG }\end{array}$ & $192-252$ & 55 & I & 4 & 0.125 & 0.675 & 0.607 & 0.064 & JX503175 \\
\hline SK494 & $(\mathrm{TG})_{16}^{9}$ & $\begin{array}{l}\text { F: TGA } \\
\text { R: GAC }\end{array}$ & $300-340$ & 55 & $\mathrm{P}$ & 5 & 0.500 & 0.720 & 0.658 & 0.058 & JX503173 \\
\hline SK498 & $(\mathrm{GT})_{17}$ & $\begin{array}{l}\text { F: CTT } \\
\text { R: GTT }\end{array}$ & $228-298$ & 55 & $P$ & 6 & 0.750 & 0.796 & 0.750 & 0.052 & JX503169 \\
\hline SK509 & $(\mathrm{CA})_{15}$ & $\begin{array}{l}\text { F: AGC } \\
\text { R:AGT }\end{array}$ & $262-323$ & 55 & $\mathrm{P}$ & 6 & 1.000 & 0.715 & 0.662 & $0.000^{*}$ & JX503158 \\
\hline SK516 & $(\mathrm{GT})_{20}$ & $\begin{array}{l}\text { CTTGTGTTAGC } \\
\text { CGTTTCTCAGA }\end{array}$ & $260-344$ & 55 & $\mathrm{P}$ & 4 & 0.844 & 0.668 & 0.602 & 0.098 & JX503151 \\
\hline SK519 & $(\mathrm{TG})_{20}$ & $\begin{array}{l}\text { F: TACAGCAGGCAATCAATG } \\
\text { R: GGGTGTGCTGTCAGTCAA }\end{array}$ & 14 & 60 & $P$ & 8 & 0.969 & 0.683 & 0.616 & 0.022 & JX503372 \\
\hline SK524 & $\begin{array}{l}(\mathrm{TC})_{6} \mathrm{~N}(\mathrm{TC})_{9} \mathrm{~N} \\
(\mathrm{TG})_{6}\end{array}$ & $\begin{array}{l}\text { F: GCTTTCATCACCGCTTCT } \\
\text { R: GACGCCATTATTGATGCT }\end{array}$ & 06 & 55 & I & 5 & 0.500 & 0.692 & 0.623 & 0.107 & JX503367 \\
\hline SK530 & (AC) & $\begin{array}{l}\text { F: CTGAAGACAAAGACCCGCTA } \\
\text { R: CCTTGTGACAGTGTTTCAGTTC }\end{array}$ & 1 & 58 & $\mathrm{P}$ & 8 & 0.469 & 0.759 & 0.722 & 0.349 & JX503361 \\
\hline SK532 & $(\mathrm{TG})_{12}$ & $\begin{array}{l}\text { AGAGGAAGGT } \\
\text { TATCTGGAGCAC }\end{array}$ & $187-238$ & 55 & $\mathrm{P}$ & 8 & 1.000 & 0.842 & 0.807 & 0.004 & JX503359 \\
\hline SK533 & $(\mathrm{TG})_{17}$ & $\begin{array}{l}\text { CA } \\
\text { GTTTG }\end{array}$ & 2 & 60 & $\mathrm{P}$ & 4 & 0.813 & 0.743 & 0.683 & 0.056 & JX503358 \\
\hline SK534 & $(\mathrm{TG})_{6}$ & $\begin{array}{l}\text { F: TGA } \\
\text { R: GCG }\end{array}$ & 213-254 & 58 & $\mathrm{P}$ & 6 & 0.781 & 0.809 & 0.767 & 0.615 & JX503357 \\
\hline SK53 & $(\mathrm{CA})_{11}$ & $\begin{array}{l}\text { GGGGAAGAATAAGT } \\
\text { ACAGCACTATCATC }\end{array}$ & 1 & 58 & $P$ & 6 & 1.000 & 0.741 & 0.687 & 0.324 & $\mathrm{~J} 2$ \\
\hline SK54 & $\begin{array}{l}(\mathrm{GT})_{7} \mathrm{~N}(\mathrm{AC})_{10} \mathrm{~N} \\
(\mathrm{AC})_{6}\end{array}$ & $\begin{array}{l}\text { F: AGCCGAACTACATCAACAA } \\
\text { R: TCTTCCAACCTCAGAGATAAC }\end{array}$ & 285-314 & 55 & I & 3 & 0.000 & 0.514 & 0.450 & 0.163 & $\mathrm{~J}$ \\
\hline SK5 & (CTC & $\begin{array}{l}\text { F: TGCCTGTAGTTGCTGTTGCT } \\
\text { R: CGGTGTGAAAACTGAAGGT }\end{array}$ & 10 & 58 & P & 3 & 0.313 & 0.518 & 0.457 & 0.381 & JX503 \\
\hline SK5 & $(\mathrm{CA})_{15}$ & $\begin{array}{l}\text { F: TGACGAGGAAGACAGAGACG } \\
\text { R: GCAGCAAAGTGGATTGTAGC }\end{array}$ & 3 & 60 & P & 7 & 1.000 & 0.826 & 0.787 & 0.003 & 3347 \\
\hline SK546 & $\begin{array}{l}(\mathrm{AAT})_{6} \mathrm{~N} \\
(\mathrm{AAAT})_{3}\end{array}$ & $\begin{array}{l}\text { F: CTGAGGCTGAGCTGGATT } \\
\text { R: GAAGGTGTTGTACCAGATGTG }\end{array}$ & $206-258$ & 58 & I & 4 & 0.594 & 0.515 & 0.468 & 0.575 & JX503345 \\
\hline SK559 & & $\begin{array}{l}\text { F: GTTCGTTCTTCCCTGATGCT } \\
\text { R: AGTTGCTGCCAATCAAACCA }\end{array}$ & $200-236$ & 58 & $\mathrm{P}$ & 4 & 0.469 & 0.709 & 0.640 & 0.236 & JX503332 \\
\hline SK560 & $(\mathrm{GT})$ & $\begin{array}{l}\text { F: GTAATACTGTTGCACTTCGT } \\
\text { R: GTAGGCATCAAGTGAAGC }\end{array}$ & $270-320$ & 55 & $\mathrm{P}$ & 3 & 0.375 & 0.372 & 0.309 & 0.546 & JX503331 \\
\hline SK565 & $(\mathrm{GT})_{12}$ & $\begin{array}{l}\text { F: TAGACGAGGGTATATGTGGA } \\
\text { R: GAGGGAAATGATGGACTACTAC }\end{array}$ & ${ }^{171-226}$ & 58 & $\mathrm{P}$ & 3 & 0.031 & 0.372 & 0.309 & 0.381 & JX503326 \\
\hline SK5 & $\begin{array}{l}(\mathrm{TA})_{8} \mathrm{~N} \\
(\mathrm{CTT})_{4}\end{array}$ & $\begin{array}{l}\text { F: AGCACCCACCTCATTTCAGT } \\
\text { R: AGGATTTGCTGTGTTCACATAG }\end{array}$ & $282-305$ & 58 & I & 3 & 0.938 & 0.600 & 0.503 & 0.000 & JX503324 \\
\hline SK & & $\begin{array}{l}\text { F: TCTCCTCTTCTTCGTCGTCC } \\
\text { R: CGAGATTAGCGGTGAATTGA }\end{array}$ & $262-303$ & 60 & $P$ & 5 & 1.000 & 0.782 & 0.732 & 0.133 & JX503322 \\
\hline SK574 & $\begin{array}{c}(\mathrm{AC})_{8} \mathrm{~N}(\mathrm{AC})_{7} \\
\mathrm{~N}(\mathrm{AGG})_{4} \mathrm{~N} \\
(\mathrm{GCAC})_{3}\end{array}$ & $\begin{array}{l}\text { F: CAGCAAGATCCGTAACGC } \\
\text { R: GTCGCTACACCTACCTGGAG }\end{array}$ & $300-345$ & 60 & I & 6 & 1.000 & 0.806 & 0.001 & 0.761 & JX503317 \\
\hline
\end{tabular}

Continued on next page 


\begin{tabular}{|c|c|c|c|c|c|c|c|c|c|c|c|}
\hline Locus name & Repeat motif & Primer sequence $\left(5^{\prime}-3^{\prime}\right)$ & $\begin{array}{l}\text { Size range } \\
\quad \text { (bp) }\end{array}$ & $\begin{array}{cc}\mathrm{Ta} & \mathrm{I} \\
\left({ }^{\circ} \mathrm{C}\right) & \end{array}$ & $\begin{array}{l}\text { Locus } \\
\text { type }\end{array}$ & $N_{\mathrm{A}}$ & $H_{\mathrm{O}}$ & $H_{\mathrm{E}}$ & PIC & $\mathrm{P}_{\mathrm{HWE}}$ & $\begin{array}{c}\text { GenBank } \\
\text { accession } \\
\text { No. }\end{array}$ \\
\hline \multicolumn{12}{|c|}{ Transcriptome-derived SSR } \\
\hline SK578 & $(\mathrm{TG})_{23}$ & $\begin{array}{l}\text { F: AGTCTCTGGGCGAAGTGT } \\
\text { R: GGATCTGCTAACCTGTAACTGTC }\end{array}$ & $196-250$ & 58 & $P$ & 6 & 0.969 & 0.835 & 0.797 & 0.017 & JX503313 \\
\hline SK580 & $(\mathrm{ACTA})_{5}$ & $\begin{array}{l}\text { F: TCATCAGCAGTGTTGGTAAT } \\
\text { R: GCCATTGTATAAGAAGAACACAC }\end{array}$ & $\mathrm{G}^{318-394}$ & 55 & $P$ & 6 & 0.781 & 0.819 & 0.778 & 0.619 & JX503311 \\
\hline SK592 & $(\mathrm{TG})_{12}$ & $\begin{array}{l}\text { F: AGCAACCCAATGTTACTCTT } \\
\text { R: AACAAAGCCATTAGATCGTC }\end{array}$ & $191-270$ & 55 & $\mathrm{P}$ & 5 & 0.250 & 0.801 & 0.755 & 0.035 & JX503299 \\
\hline SK603 & $(\mathrm{GT})_{13}$ & $\begin{array}{l}\text { F: CCACTTGGTCAATGAAATGT } \\
\text { R: GCCCTGTGTCATAACTCAATC }\end{array}$ & $187-240$ & 58 & $P$ & 7 & 0.875 & 0.807 & 0.765 & 0.840 & JX503288 \\
\hline SK607 & $(\mathrm{ACA})_{5}$ & $\begin{array}{l}\text { F: CAAGAACCCACCGAGAAAC } \\
\text { R: TGCCACCTTTAGATTTCAGC }\end{array}$ & $195-231$ & 58 & $\mathrm{P}$ & 3 & 0.125 & 0.230 & 0.215 & 0.821 & JX503284 \\
\hline SK608 & $(\mathrm{GT})_{34}$ & $\begin{array}{l}\text { F: TGGGTAGGCTTCATGTGGTA } \\
\text { R: CACTCCACTGAATTGAATGTAGG }\end{array}$ & $\mathrm{G}^{125-205}$ & 58 & $\mathrm{P}$ & 5 & 0.469 & 0.753 & 0.698 & 0.076 & JX503283 \\
\hline SK609 & $(\mathrm{GAG})_{5}$ & $\begin{array}{l}\text { F: GCATCAGAAGGTGAAGAGA } \\
\text { R: AACCTCCTCAATGTTTGTC }\end{array}$ & $183-294$ & 55 & $P$ & 6 & 0.938 & 0.765 & 0.711 & 0.248 & JX503282 \\
\hline SK613 & $(\mathrm{AC})_{12}$ & $\begin{array}{l}\text { F: ACTGCCTTGTCAATAGCGGT } \\
\text { R: GGTGATGATGGAGAGAAGTGTAC }\end{array}$ & $\mathrm{G}^{146-211}$ & 60 & $\mathrm{P}$ & 8 & 0.969 & 0.857 & 0.824 & 0.041 & JX503278 \\
\hline SK616 & $(\mathrm{GAG})_{5}$ & $\begin{array}{l}\text { F: GAAGGAGGAGGCGTGTCAT } \\
\text { R: GCCAACAACATCGTCAGAGA }\end{array}$ & 189-205 & 60 & $P$ & 3 & 0.000 & 0.564 & 0.456 & 0.032 & JX503275 \\
\hline SK624 & $\begin{array}{l}(\mathrm{AT})_{10} \mathrm{~N} \\
(\mathrm{TGTT})_{3}\end{array}$ & $\begin{array}{l}\text { F: AGCTCAGTTTCACCTGTCAC } \\
\text { R: GCTTGCGGTATAATCCAGTC }\end{array}$ & $172-205$ & 60 & I & 2 & 0.500 & 0.381 & 0.305 & 0.081 & JX503267 \\
\hline $\begin{array}{l}\text { Mean } \\
\text { Genomic SSR }\end{array}$ & & & & & & 5.1 & 0.666 & 0.692 & 0.638 & & \\
\hline FC0572 & $\begin{array}{l}(\mathrm{TG})_{14} \mathrm{~N} \\
(\mathrm{TG})_{7}\end{array}$ & $\begin{array}{l}\text { F: CTGTTGGGAGGATTTCAGTA } \\
\text { R: AACATACCTTCATAACGGTC }\end{array}$ & $129-160$ & 55 & I & 5 & 0.469 & 0.521 & 0.597 & $0.000 *$ & JX449064 \\
\hline FC0580 & $(\mathrm{GT})_{24}$ & $\begin{array}{l}\text { F: CTCGTCAGGAAACGGTAAA } \\
\text { R: ATTTGAATGTATGAATGAAT }\end{array}$ & $140-154$ & 55 & $P$ & 2 & 0.000 & 0.347 & 0.674 & $0.000^{*}$ & JX449065 \\
\hline FC0661 & $(\mathrm{GT})_{21}$ & $\begin{array}{l}\text { F: AGCCTTGTGTTTATCAGACC } \\
\text { R: TAATCCAAACATGCTCACAA }\end{array}$ & 156-199 & 55 & I & 4 & 0.375 & 0.721 & 0.248 & $0.000^{*}$ & JX449071 \\
\hline FC070 & $\begin{array}{l}(\mathrm{CTC})_{6} \mathrm{~N} \\
(\mathrm{TCC})_{4}\end{array}$ & $\begin{array}{l}\text { F: ATCTGACACGATAAACCCTC } \\
\text { R: GCTGATGCTGAGGAGGAAAT }\end{array}$ & $210-246$ & 58 & I & 4 & 0.281 & 0.511 & 0.631 & 0.012 & JX449076 \\
\hline FC076 & $(\mathrm{GGA})_{9}$ & $\begin{array}{l}\text { F: TACCCCAGTCGTGTCCCTT } \\
\text { R: CTTTCCTTATTTATTGACTTC }\end{array}$ & $142-217$ & 55 & $\mathrm{P}$ & 3 & 0.250 & 0.587 & 0.481 & 0.008 & JX449082 \\
\hline FC077 & $(\mathrm{CCT})_{10}$ & $\begin{array}{l}\text { F: CAAGACCGACTGAATCCTGA } \\
\text { R: ATCCGAACAGACTTTCCATT }\end{array}$ & $203-273$ & 58 & $P$ & 5 & 0.406 & 0.399 & 0.283 & 0.021 & JX449083 \\
\hline FC0791 & $(\mathrm{TG})_{22}$ & $\begin{array}{l}\text { F: GGTATCCATCCAGGTCTAAT } \\
\text { R: CTCCTCTGAGCCTGTTCTCC }\end{array}$ & $176-211$ & 60 & $P$ & 5 & 0.406 & 0.487 & 0.661 & 0.188 & JX449085 \\
\hline FC0820 & $\begin{array}{l}(\mathrm{TG})_{29} \mathrm{~N} \\
(\mathrm{TG})_{6}\end{array}$ & $\begin{array}{l}\text { F: CACCACCAGGCTACCTCAGT } \\
\text { R: CACTGGGGAGATACACTACT }\end{array}$ & 234-291 & 60 & I & 5 & 1.000 & 0.748 & 0.462 & 0.578 & JX449087 \\
\hline FC084 & $(\mathrm{GAG})_{8}$ & $\begin{array}{l}\text { F: TTTGTGCTCCTCTGCTTGTC } \\
\text { R: TTTCAGGGTCAAGAGGTCAG }\end{array}$ & $210-224$ & 60 & $\mathrm{P}$ & 4 & 0.188 & 0.701 & 0.501 & 0.167 & JX449088 \\
\hline FC086 & $(\mathrm{CTC})_{7}$ & $\begin{array}{l}\text { F: GGAAGAAGACCCACAACATC } \\
\text { R: GGACCAACGCAACCCAGCAT }\end{array}$ & $109-216$ & 62 & $\mathrm{P}$ & 4 & 0.531 & 0.539 & 0.369 & 0.722 & JX449090 \\
\hline FC093 & $\begin{array}{l}\mathrm{G})_{14} \mathrm{~N}(\mathrm{CTC})_{6} \mathrm{~N} \\
(\mathrm{TGTGA})_{3}\end{array}$ & $\begin{array}{l}\text { F: GCCGTGATGTATCCACTCTG } \\
\text { R: CGTCCACACACCCATCACAT }\end{array}$ & $190-207$ & 62 & I & 2 & 0.000 & 0.347 & 0.452 & 0.013 & JX449095 \\
\hline FC094 & $(\mathrm{GT})_{16}$ & $\begin{array}{l}\text { F: TCCCGCATAGAGGAGTCTGT } \\
\text { R: AACTCAACGCAAGCAGGC }\end{array}$ & $126-153$ & 58 & $P$ & 3 & 0.031 & 0.201 & 0.690 & 0.010 & JX449096 \\
\hline FC095 & $(\mathrm{CTC})_{10}$ & $\begin{array}{l}\text { F: TCTGACTACAGTTCAACAGG } \\
\text { R: ATCCCAAGAAATATGGAGGC }\end{array}$ & $149-265$ & 58 & $\mathrm{P}$ & 3 & 0.063 & 0.228 & 0.635 & 0.257 & JX449097 \\
\hline FC096 & $(\mathrm{TCC})_{6}$ & $\begin{array}{l}\text { F: CACGCCTGTTTATCTCTTTG } \\
\text { R: CTCAAGAGTCCTACCATCCA }\end{array}$ & $162-224$ & 58 & $\mathrm{P}$ & 5 & 1.000 & 0.799 & 0.481 & 0.379 & JX449098 \\
\hline FC102 & $(\mathrm{TCC})_{9}$ & $\begin{array}{l}\text { F: GTTTGTGTCGTATATGACGG } \\
\text { R: CTCCTCCTTGGTCTTGAGAT }\end{array}$ & 121-189 & 58 & $P$ & 4 & 0.563 & 0.653 & 0.283 & 0.245 & JX449104 \\
\hline FC104 & $\begin{array}{c}(\mathrm{GGA})_{5} \mathrm{~N} \\
(\mathrm{GAG})_{5} \mathrm{~N} \\
(\mathrm{AGC})_{5} \mathrm{~N} \\
(\mathrm{AGA})_{5}\end{array}$ & $\begin{array}{l}\text { F: CCAGTTCAGGAGGTGGCG } \\
\text { R: TGCAGAAGAGCTATGTAAGG }\end{array}$ & $182-238$ & 58 & I & 5 & 0.656 & 0.729 & 0.183 & 0.321 & JX449106 \\
\hline FC105 & $\begin{array}{l}(\mathrm{CTC})_{5} \mathrm{~N} \\
(\mathrm{CCT})_{4}\end{array}$ & $\begin{array}{l}\text { F: CAGTTCAACAGGACTATGGG } \\
\text { R: GGAGGCGTTGAAGGAATAAT }\end{array}$ & $141-225$ & 58 & I & 3 & 0.063 & 0.276 & 0.210 & $0.000^{*}$ & JX449107 \\
\hline FC108 & $(\mathrm{TCC})_{7}$ & $\begin{array}{l}\text { F: TAGTGGCAATCAGGATGAAA } \\
\text { R: CGTCTTTTTAGATTCCTCGC }\end{array}$ & $207-288$ & 55 & $\mathrm{P}$ & 4 & 0.563 & 0.696 & 0.753 & 0.140 & JX449109 \\
\hline Mean & & & & & & 3.8 & 0.380 & 0.527 & 0.477 & & \\
\hline
\end{tabular}

$\mathrm{P}=$ pure; $\mathrm{I}=$ interrupted. *Show significant deviation from HWE after Bonferroni's correction $(\mathrm{P}<0.0009)$. 


\section{Data analysis}

The number of alleles $\left(N_{\mathrm{A}}\right)$, observed heterozygosities $\left(H_{\mathrm{O}}\right)$, and expected heterozygosities $\left(H_{\mathrm{E}}\right)$ were computed by the POPGENE software (Version 3.2) (Yeh and Boyle, 1997). The polymorphic information content (PIC) was calculated by the formula:

$$
P I C=1-\left(\sum_{i=1}^{n} q_{i}^{2}\right)-\left(\sum_{i=1}^{n-1} \sum_{j=i+1}^{n} 2 q_{i}^{2} q_{j}^{2}\right)
$$

where $q i$ and $q j$ is the $i^{\text {th }}$ and $j^{\text {th }}$ allele frequency, respectively, while $n$ is the number of alleles (Botstein et al., 1980). The exact test for genotypic linkage disequilibrium and the exact tests for conformation to Hardy-Weinberg equilibrium (HWE) at each locus were performed using the GENEPOP version 1.2 program (Raymond and Rousset, 1995). The SSR markers were classified by Weber's rules (1990). Null alleles among loci were detected by the MicroChecker V.2.2.3 software (Van Oosterhout et al., 2004). All results were adjusted for multiple simultaneous comparisons using sequential Bonferroni's correction (Holm, 1979).

\section{RESULTS}

A total of 356 unique candidate sequences containing SSR motifs were selected from the transcriptome of the $\mathrm{F}_{1}$ interspecies hybrids between S. chuatsi (ㅇ) and S. scherzeri (ठ)). One hundred and seventy-two SSR-containing sequences (GenBank accession Nos. JX503150JX503199 and JX503252-JX503373) flanked by suitable priming sites were selected for conversion into SSR markers. From the SSR-enriched gnomic libraries, 576 positive clones were selected and sequenced. Among these clones, 220 sequences were found to contain SSR motifs with 6 or more repeat nucleotide. We designed 60 primer pairs from the sequences with sufficient flanking region (GenBank accession Nos. JX449062-JX449139). One hundred and thirty-six transcriptome primer pairs and 49 genomic primer pairs produced clear amplified products by SSR-PCR amplification. These primers were further examined for polymorphism with $S$. kneri collected from 4 populations across China: Guangdong, Guangxi, Hubei, and Hunan (8 individuals from each population). Finally, 55 SSR markers (37 from transcriptome and 18 from genomic) displayed polymorphisms, while the other markers displayed monomorphisms.

The characteristics of the polymorphic and monomorphic SSR markers are shown in Tables 1 and 2, respectively. The average $N_{\mathrm{A}}$ per locus was 5.1 (range: 2-8) for transcriptomederived SSRs and 3.8 (range: 2-5) for genomic SSRs. The average $H_{\mathrm{O}}$ and $H_{\mathrm{E}}$ were 0.666 (range: $0.000-1.000$ ) and 0.692 (range: $0.230-0.857$ ) for transcriptome-derived SSRs, respectively. These values were 0.380 (range: 0.000-1.000) and 0.527 (range: 0.201-0.799) for genomic SSRs, respectively. The PIC was 0.638 (range: $0.215-0.824$ ) for transcriptome-derived SSRs and 0.477 (range: $0.183-0.752$ ) for genomic SSRs. There were $72 \%$ of di-nucleotide repeats, $16 \%$ of trinucleotide and $8 \%$ of tetra-nuleotide among EST-SSR markers, and $63 \%$ of tri-nucleotide, $24 \%$ of di-nucleotide and 13\% of penta-nucleotide among genomic SSR markers. Seven of these loci exhibited departure from HWE after sequential Bonferroni's correction for multiple tests, and no significant deviation was observed for the linkage disequilibrium. Null alleles were not detected among any of the loci in the analysis of the allelic inheritance mode. The results revealed no significant instances of linkage disequilibrium following the Bonferroni correction, indicating the independent behavior of all loci. 
Table 2. Characterization of all microsatellite markers (polymorphic markers excluded) including locus name, Genbank accession number, repeat motif, annealing temperature (Ta), locus type, and primer sequences.

\begin{tabular}{|c|c|c|c|c|c|}
\hline Locus name & GenBank accession No. & Repeat motif & $\mathrm{Ta}\left({ }^{\circ} \mathrm{C}\right)$ & Locus type & Primer sequence (5'-3') \\
\hline \multicolumn{6}{|c|}{ Transcriptome-derived SSR } \\
\hline SK468 & JX503199 & $(\mathrm{CA})_{11}$ & 55 & $\mathrm{P}$ & $\begin{array}{l}\text { F:AGCAGAGACAGCAGGGAATG } \\
\text { R:ATACCGCTGCAACCCTAGTG }\end{array}$ \\
\hline SK469 & JX503198 & $(\mathrm{AGG})_{7}$ & 53.5 & $\mathrm{P}$ & $\begin{array}{l}\text { F:GAGCATCCAGGAAGTAGACT } \\
\text { R:ACCGAGTATCTCACCCATCT }\end{array}$ \\
\hline SK470 & JX503197 & $(\mathrm{TCT})_{5}$ & 56 & $\mathrm{P}$ & $\begin{array}{l}\text { F:AGCAGCAGGAGTCGGAGA } \\
\text { R:TCCTCTTCGTCCACTGATGA }\end{array}$ \\
\hline SK471 & JX503196 & $(\mathrm{AAT})_{11}$ & 53.5 & $\mathrm{P}$ & $\begin{array}{l}\text { F:GGCGACGATAGGTGAATAAG } \\
\text { R:CGAGCCTGTTTACTGCATAG }\end{array}$ \\
\hline SK474 & JX503193 & $(\mathrm{GGA})_{6}$ & 53.5 & $\mathrm{P}$ & $\begin{array}{l}\text { F:CAAGAAACAGGCTGTGGT } \\
\text { R:GGCTTCCTCATTGTATCAGA }\end{array}$ \\
\hline SK475 & JX503192 & $(\mathrm{GT})_{15}(\mathrm{GC})_{9}$ & 56 & $\mathrm{C}$ & $\begin{array}{l}\text { F:AGAATCTACACACAGCAGCACA } \\
\text { R:CGTGGAGAGCGTCTTTTCTA }\end{array}$ \\
\hline SK476 & JX503191 & $(\mathrm{TCC})_{6}$ & 57.5 & $\mathrm{P}$ & $\begin{array}{l}\text { F:TCCCTCACAGTTGGTGTC } \\
\text { R:GTCTGCACTACCTGGAGTC }\end{array}$ \\
\hline SK477 & JX503190 & $(\mathrm{TCA})_{4} \mathrm{~N}(\mathrm{TCA})_{9}$ & 53.5 & I & $\begin{array}{l}\text { F:CAGAAATGGTGTGGATGCT } \\
\text { R:TAGGCGGAACAGAGGTAATA }\end{array}$ \\
\hline SK478 & JX503189 & $(\mathrm{ATG})_{9}$ & 53.5 & $\mathrm{P}$ & $\begin{array}{l}\text { F:AACGGACGGAAAGACAGA } \\
\text { R:TCCAACAGGTGTAAACAGTAGA }\end{array}$ \\
\hline SK479 & JX503188 & $(\mathrm{TG})_{6} \mathrm{~N}(\mathrm{AC})_{8}$ & 53.5 & I & $\begin{array}{l}\text { F:TACTGTTTACACCTGTTGGA } \\
\text { R:TGAATCTCTCAGAATTGCTG }\end{array}$ \\
\hline SK480 & JX503187 & $(\mathrm{GGA})_{5}$ & 53.5 & $\mathrm{P}$ & $\begin{array}{l}\text { F:TTCACCCAGCAATAATAGAG } \\
\text { R:CCTCGGTTTATGTGGTAGTA }\end{array}$ \\
\hline SK481 & JX503186 & $(\mathrm{GGT})_{5}$ & 53.5 & $\mathrm{P}$ & $\begin{array}{l}\text { F:TGAAGGCAATCTGAGGCAAC } \\
\text { R:CCAGACGGAAGAGGAAGTGA }\end{array}$ \\
\hline SK482 & JX503185 & $(\mathrm{TTG})_{11}$ & 53.5 & $\mathrm{P}$ & $\begin{array}{l}\text { F:CACATTTGACATGACAAGAC } \\
\text { R:ATCCTTGGACAGCATTATAC }\end{array}$ \\
\hline SK484 & JX503183 & $(\mathrm{GA}) 10 \mathrm{~N}(\mathrm{TG})_{11}$ & 53.5 & I & $\begin{array}{l}\text { F:AAACAGCAGCCCACAGGAAG } \\
\text { R:TGCCTGGAACATCACCCTGG }\end{array}$ \\
\hline SK485 & JX503182 & $(\text { TGTT })_{7}$ & 53.5 & P & $\begin{array}{l}\text { F:AGATAGGAGGGCAGTAAAGA } \\
\text { R:GAATGACCTACCAAGAATGT }\end{array}$ \\
\hline SK486 & JX503181 & $(\mathrm{ATT})_{5}$ & 55.5 & $\mathrm{P}$ & $\begin{array}{l}\text { F:CATTTCTTCCCGATGTTAGA } \\
\text { R:CGGCAACTATTCTCATAACC }\end{array}$ \\
\hline SK487 & JX503180 & $(\mathrm{TCC})_{5} \mathrm{~N}(\mathrm{TCC})_{5}$ & 55.5 & I & $\begin{array}{l}\text { F:TCCTCCTTTTTCACATCGG } \\
\text { R:GAAATCTGTCAGGAGCCGTT }\end{array}$ \\
\hline SK488 & JX503179 & $(\mathrm{CT})_{6}(\mathrm{TCAC})_{3} \mathrm{~N}(\mathrm{CCT})_{7}$ & 55.5 & I & $\begin{array}{l}\text { F:CCCTCTCCCGGACTGACA } \\
\text { R:CAGAGTTTCATCCTCTCAGC }\end{array}$ \\
\hline SK489 & JX503178 & $(\mathrm{AC})_{7} \mathrm{~N}(\mathrm{AC})_{11}$ & 55.5 & I & $\begin{array}{l}\text { F:TACTGACTGCTTAACTGTGC } \\
\text { R:TTCCCACCAACCTCTCGCAT }\end{array}$ \\
\hline SK493 & JX503174 & $(\mathrm{CTT})_{7}$ & 55.5 & $\mathrm{P}$ & $\begin{array}{l}\text { F:TCCACACACGAACATCACAA } \\
\text { R:CGTCTGTCTCTCCTCATCTT }\end{array}$ \\
\hline SK495 & JX503172 & $(\mathrm{TG})_{10} \mathrm{~N}(\mathrm{AG})_{6}$ & 53.5 & I & $\begin{array}{l}\text { F:AATCAGTAGCCACAGCGTGT } \\
\text { R:TTTGAGATTATGGGGTGCGA }\end{array}$ \\
\hline SK496 & JX503171 & $(\mathrm{GAG})_{6}$ & 55 & $\mathrm{P}$ & $\begin{array}{l}\text { F:GACAGGTCCCTGGTCTCAAC } \\
\text { R:ATGGTGAAGTCAGGAGACGC }\end{array}$ \\
\hline SK497 & JX503170 & $(\mathrm{CT})_{7}(\mathrm{CA})_{7} \mathrm{~N}(\mathrm{CA})_{10}$ & 53.5 & I & $\begin{array}{l}\text { F:GTGTGTAAGGCCCTACTCTC } \\
\text { R:TTGCTCTCACTCACTCTGCT }\end{array}$ \\
\hline SK499 & JX503168 & $(\mathrm{GAT})_{5} \mathrm{~N}(\mathrm{GAC})_{4}$ & 53.5 & I & $\begin{array}{l}\text { F:GATAAGGTGAGGCAAAACAT } \\
\text { R:GCATCAACCTCGTCCTTACC }\end{array}$ \\
\hline SK500 & JX503167 & $(\mathrm{GTT})_{6}$ & 55.5 & $\mathrm{P}$ & $\begin{array}{l}\text { F:ATGACGGCCACTGTTCCAAT } \\
\text { R:GCCGACCAACCACATCTTCT }\end{array}$ \\
\hline SK501 & JX503166 & $(\mathrm{GT})_{9} \mathrm{~N}(\mathrm{GT})_{10}$ & 55.5 & I & $\begin{array}{l}\text { F:CGAAAGATGGGAGGAGGAA } \\
\text { R:GCATGGCTTTGATTTGACC }\end{array}$ \\
\hline SK502 & JX503165 & $(\mathrm{AAG})_{5}$ & 55.5 & $\mathrm{P}$ & $\begin{array}{l}\text { F:TACTGCCAGGAAGGTGTTA } \\
\text { R:CTTTGTGGTGACAGGAGTC }\end{array}$ \\
\hline SK503 & JX503164 & $(\mathrm{AG})_{12}$ & 53.5 & $\mathrm{P}$ & $\begin{array}{l}\text { F:CCATTGTGCGAGAGATGTGC } \\
\text { R:CTGGGTGCTGTAGGCAGTAG }\end{array}$ \\
\hline SK504 & JX503163 & $(\mathrm{AATAG})_{3}$ & 55 & $\mathrm{P}$ & $\begin{array}{l}\text { F:CACAGGCTAATGGATAGATA } \\
\text { R:GATTCAGCAAATGCCTTCAG }\end{array}$ \\
\hline SK505 & JX503162 & $(\mathrm{TG})_{20}$ & 53.5 & P & $\begin{array}{l}\text { F:AAAGGGTTAGGGTTAGAGTT } \\
\text { R:CCTCATCTCTGCCTCATACT }\end{array}$ \\
\hline
\end{tabular}




\begin{tabular}{|c|c|c|c|c|c|}
\hline Locus name & GenBank accession No. & Repeat motif & $\mathrm{Ta}\left({ }^{\circ} \mathrm{C}\right)$ & Locus type & Primer sequence (5'-3') \\
\hline \multicolumn{6}{|c|}{ Transcriptome-derived SSR } \\
\hline SK506 & JX503161 & $(\mathrm{TGG})_{6}$ & 54 & $\mathrm{P}$ & $\begin{array}{l}\text { F:CAGCGTGTGTTGTTCCGTAG } \\
\text { R:GAACCTCTGCCTACTCCTGC }\end{array}$ \\
\hline SK507 & JX503160 & $(\mathrm{AGG})_{5}$ & 54 & $\mathrm{P}$ & $\begin{array}{l}\text { F:CCTCTGGAAAAGGCAAAGCA } \\
\text { R:AGCCGTCTTCTGTTTACTTC }\end{array}$ \\
\hline SK508 & JX503159 & $(\mathrm{TTC})_{5}$ & 55 & $\mathrm{P}$ & $\begin{array}{l}\text { F:TCGGCGATGCTGAGAAACCA } \\
\text { R:AACAGGAAGTGACAGAGGAG }\end{array}$ \\
\hline SK510 & JX503157 & $(\mathrm{CAG})_{5}$ & 55.5 & $\mathrm{P}$ & $\begin{array}{l}\text { F:GAGAACTGGGAGGAGAGATG } \\
\text { R:TCACAGACACCTCCAGGGAT }\end{array}$ \\
\hline SK511 & JX503156 & $(\mathrm{CA})_{26}$ & 55 & $\mathrm{P}$ & $\begin{array}{l}\text { F:GAAGCCCAGCAAAGAGAACA } \\
\text { R:CACCTACATCTACATTTTGA }\end{array}$ \\
\hline SK512 & JX503155 & $(\mathrm{TCC})_{14}$ & 54.5 & $\mathrm{P}$ & $\begin{array}{l}\text { F:CTGTGAGGCTTCAAACCGTC } \\
\text { R:ACTCACAATGCTACGACAAG }\end{array}$ \\
\hline SK513 & JX503154 & $(\mathrm{CTG})_{4}$ & 54 & $\mathrm{P}$ & $\begin{array}{l}\text { F:TCCATAGGGTTCGTAGCGTC } \\
\text { R:TTTGAAGGTGCTTGACTCGT }\end{array}$ \\
\hline SK514 & JX503153 & $(\mathrm{ATTT})_{5}$ & 55.5 & $\mathrm{P}$ & $\begin{array}{l}\text { F:TCAGACAGAAGCTCAGCAAT } \\
\text { R:GGAAGTGACAAACCAAATC }\end{array}$ \\
\hline SK515 & JX503152 & $(\mathrm{CAG})_{6} \mathrm{~N}(\mathrm{CAG})_{4}$ & 58 & I & $\begin{array}{l}\text { F:GCTGCTCTGGTCCAACAACA } \\
\text { R:CGCCTGTCGTTCTCTCTCCT }\end{array}$ \\
\hline SK517 & $\mathrm{JX} 503150$ & $(\mathrm{GAG})_{5}$ & 53.5 & $\mathrm{P}$ & $\begin{array}{l}\text { F:TCGTGTGGAGATGTCAACAG } \\
\text { R:ACGGCTCCTGCTGTGGCTA }\end{array}$ \\
\hline SK518 & JX503373 & $(\mathrm{TG})_{11}$ & 60 & $\mathrm{P}$ & $\begin{array}{l}\text { F:AAGAAGACGCAAGTTGGGAG } \\
\text { R:ACCCTGCCATTAGCCATTAG }\end{array}$ \\
\hline SK520 & JX503371 & $(\mathrm{CT})_{12}$ & 58 & $\mathrm{P}$ & $\begin{array}{l}\text { F:AACAATGACTCAATCCTTCCC } \\
\text { R:ACACGTCAGAGTCAGGCAG }\end{array}$ \\
\hline SK521 & JX503370 & $(\mathrm{AC})_{24}$ & 58 & $\mathrm{P}$ & $\begin{array}{l}\text { F:CTGCCAACACTAACCTCTGA } \\
\text { R:GCAAAGCCAGTACAGCCA }\end{array}$ \\
\hline SK522 & JX503369 & $(\mathrm{CTC})_{5}$ & 58 & $\mathrm{P}$ & $\begin{array}{l}\text { F:TCCACCTCACCGATATAAGT } \\
\text { R:AGAGTATGTGTGGAGGTGAA }\end{array}$ \\
\hline SK523 & JX503368 & $(\mathrm{GAG})_{5}$ & 58 & $\mathrm{P}$ & $\begin{array}{l}\text { F:TCACAGTGAGGAGGTGCT } \\
\text { R:TATTCCTGCTGACACTGC }\end{array}$ \\
\hline SK525 & JX503366 & $(\mathrm{AC})_{12}$ & 55 & $\mathrm{P}$ & $\begin{array}{l}\text { F:CACTGCATTGTAACTTCTTG } \\
\text { R:ATGGACTATTGATGATGTACTG }\end{array}$ \\
\hline SK526 & JX503365 & $(\mathrm{GT})_{7}$ & 55 & $\mathrm{P}$ & $\begin{array}{l}\text { F:GACCATTCCTCCAGTCAT } \\
\text { R:TGCACCCTTGCTACTCTA }\end{array}$ \\
\hline SK527 & JX503364 & $(\mathrm{GTT})_{5} \mathrm{~N}(\mathrm{TGT})_{4}$ & 55 & I & $\begin{array}{l}\text { F:GTACGACTCCTGCTGTCCT } \\
\text { R:TACCCACAACAACAACAGA }\end{array}$ \\
\hline SK528 & JX503363 & $(\mathrm{GCT})_{7} \mathrm{~N}(\mathrm{TGT})_{3}$ & 55 & I & $\begin{array}{l}\text { F:TTGGCAGGCATCATAGGG } \\
\text { R:GTCGGGGAGCAGTTTCTACC }\end{array}$ \\
\hline SK529 & JX503362 & $(\mathrm{CCT})_{5}$ & 58 & $\mathrm{P}$ & $\begin{array}{l}\text { F:CTACCCTCCCTCTCATCACC } \\
\text { R:TCTGCCAGATTCAGTAATGC }\end{array}$ \\
\hline SK531 & JX503360 & $(\mathrm{AAAC})_{5}$ & 60 & $\mathrm{P}$ & $\begin{array}{l}\text { F:CCTCCAGCCCTGTACTTCTA } \\
\text { R:CTTTTGGACTCTGGACTCTG }\end{array}$ \\
\hline SK535 & JX503356 & $(\mathrm{TC})_{6} \mathrm{~N}(\mathrm{CA})_{7}$ & 58 & I & $\begin{array}{l}\text { F:CTCCACATAGCACCTTCAAA } \\
\text { R:GCATGACACACAAGGTTACG }\end{array}$ \\
\hline SK536 & JX503355 & $(\mathrm{GT})_{7}$ & 58 & $\mathrm{P}$ & $\begin{array}{l}\text { F:CAGAGGGAACCCATTCTACT } \\
\text { R:AAACTCCCCAGAGCAGACAC }\end{array}$ \\
\hline SK537 & JX503354 & $(\mathrm{CTG})_{4} \mathrm{~N}(\mathrm{CTG})_{5} \mathrm{~N}(\mathrm{CTC})_{6}$ & 55 & I & $\begin{array}{l}\text { F:CCTCTTTGTTTCCTCCTCACG } \\
\text { R:GAAGAGAGGAAGCGGTTAGAA }\end{array}$ \\
\hline SK539 & JX503352 & $(\mathrm{TCC})_{4}$ & 58 & $\mathrm{P}$ & $\begin{array}{l}\text { F:AGGCATCCAGATGACGAA } \\
\text { R:AATGTCAGACACCAAGCAG }\end{array}$ \\
\hline SK540 & JX503351 & $(\mathrm{AC})_{7}$ & 58 & $\mathrm{P}$ & $\begin{array}{l}\text { F:TCACTTGGTGTTGATGAGGA } \\
\text { R:ATCTTACTGAAGCCGATGAG }\end{array}$ \\
\hline SK542 & JX503349 & $(\mathrm{AC})_{11}(\mathrm{CA})_{6}$ & 58 & $\mathrm{C}$ & $\begin{array}{l}\text { F:AACACACTGGTCGTTAATGC } \\
\text { R:GAGGACATGACTCAGGTGTAC }\end{array}$ \\
\hline SK545 & JX503346 & $(\mathrm{GAG})_{5}$ & 60 & $\mathrm{P}$ & $\begin{array}{l}\text { F:CCTACAGCAAGTTCCAACAC } \\
\text { R:GACTTGACCTTGCCACATT }\end{array}$ \\
\hline SK547 & JX503344 & $(\mathrm{GCA})_{8}$ & 60 & $\mathrm{P}$ & $\begin{array}{l}\text { F:CAGTGACTCTGATGTGCCC } \\
\text { R:GCCACACAGAGTGAAGAGTT }\end{array}$ \\
\hline SK548 & JX503343 & $(\mathrm{GTCT})_{5}$ & 62 & $\mathrm{P}$ & $\begin{array}{l}\text { F:TCATGCCGTAACAGAAGTG } \\
\text { R:TATGGGGAGAGAGCTGACA }\end{array}$ \\
\hline SK549 & JX503342 & $(\mathrm{CA})_{7}$ & 55 & $\mathrm{P}$ & $\begin{array}{l}\text { F:ATCACTTGTGGTCCACTTAT } \\
\text { R:CTCGTCAATGGAAGACTAGA }\end{array}$ \\
\hline
\end{tabular}




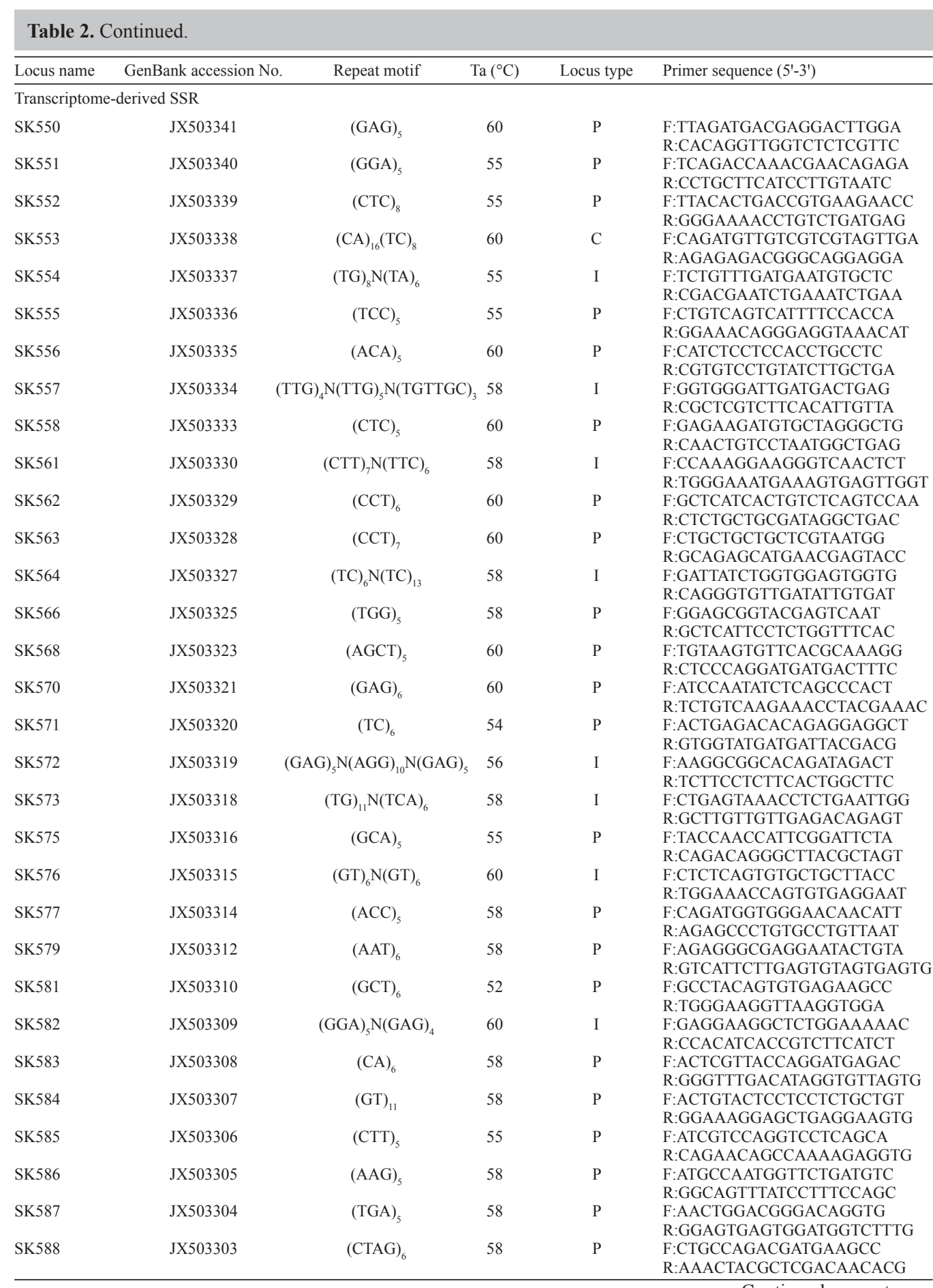

Continued on next page 


\begin{tabular}{|c|c|c|c|c|c|}
\hline Locus name & GenBank accession No. & Repeat motif & $\mathrm{Ta}\left({ }^{\circ} \mathrm{C}\right)$ & Locus type & Primer sequence $\left(5^{\prime}-3^{\prime}\right)$ \\
\hline \multicolumn{6}{|c|}{ Transcriptome-derived SSR } \\
\hline SK589 & JX503302 & $(\mathrm{ATT})_{6}$ & 55 & $\mathrm{P}$ & $\begin{array}{l}\text { F:GGTTGTTGTATATTGTTCTGC } \\
\text { R:CCTGGAGTAGTATTCACAAAG }\end{array}$ \\
\hline SK590 & JX503301 & $(\mathrm{TC})_{7}$ & 55 & $\mathrm{P}$ & $\begin{array}{l}\text { F:CGAGGGAACGTGGGTGTAA } \\
\text { R:ATTCCGCTCTCGTCCTATCA }\end{array}$ \\
\hline SK591 & JX503300 & $(\mathrm{AC})_{19}$ & 55 & $\mathrm{P}$ & $\begin{array}{l}\text { F:AATCAGAAGGACAGAAAGCA } \\
\text { R:GATTCAGTCGAGTTCATTCA }\end{array}$ \\
\hline SK593 & JX503298 & $(\mathrm{GCT})_{5} \mathrm{~N}(\mathrm{TGT})_{7}$ & 58 & I & $\begin{array}{l}\text { F:AGTCCGTCAGCTCCTCTTCA } \\
\text { R:CACCATCATCAAGTTCTTCCA }\end{array}$ \\
\hline SK594 & JX503297 & $(\mathrm{GGA})_{5}$ & 58 & $\mathrm{P}$ & $\begin{array}{l}\text { F:AGGGTGAGAGGTAGAGACAT } \\
\text { R:CCTTCAGTGTCAGATTCAGA }\end{array}$ \\
\hline SK595 & JX503296 & $(\mathrm{TC})_{16} \mathrm{~N}(\mathrm{CCT})_{4}$ & 58 & I & $\begin{array}{l}\text { F:TCACTTGCCTCTGGTGGTAT } \\
\text { R:GCACACAACGGAGGTGAAT }\end{array}$ \\
\hline SK596 & JX503295 & $(\mathrm{AGG})_{4} \mathrm{~N}(\mathrm{GGA})_{8}$ & 58 & I & $\begin{array}{l}\text { F:AGGGCTGGGAGTCAAGAGT } \\
\text { R:TGATGTCGAAGAGAATGAAGG }\end{array}$ \\
\hline SK597 & JX503294 & $(\mathrm{GT})_{6} \mathrm{~N}(\mathrm{GT})_{6}$ & 58 & I & $\begin{array}{l}\text { F:TCCAGATTACTAGAGGCAAA } \\
\text { R:TTGTGCTCACAGACATCACT }\end{array}$ \\
\hline SK598 & JX503293 & $(\mathrm{GAG})_{6}(\mathrm{GTG})_{4} \mathrm{~N}(\mathrm{GTT})_{5}$ & 55 & I & $\begin{array}{l}\text { F:TTGAGAGGCAGGACAGTA } \\
\text { R:AGTGCCAAAATAGAACAGAG }\end{array}$ \\
\hline SK599 & JX503292 & $(\mathrm{TGC})_{7} \mathrm{~N}(\mathrm{TTG})_{6} \mathrm{~N}(\mathrm{TGC})_{4}$ & 55 & I & $\begin{array}{l}\text { F:TGTGGCTGCTGGAACTGA } \\
\text { R:ACAGATGGCAAATATCAATCCC }\end{array}$ \\
\hline SK600 & JX503291 & $(\mathrm{CA})_{19}$ & 58 & $\mathrm{P}$ & $\begin{array}{l}\text { F:TTGGACGGTAAGTGTAATCTC } \\
\text { R:TGCTCAAGTTATGTGTCGTG }\end{array}$ \\
\hline SK601 & JX503290 & $(\mathrm{CCT})_{8}$ & 58 & $\mathrm{P}$ & $\begin{array}{l}\text { F:GCAGGGTTTTAATCCGACAAT } \\
\text { R:CGGAGGCTCGATGAGGAA }\end{array}$ \\
\hline SK602 & JX503289 & $(\mathrm{AAG})_{7}(\mathrm{GAG})_{4}$ & 58 & $\mathrm{C}$ & $\begin{array}{l}\text { F:CGAACCAAACGCATTAGG } \\
\text { R:GGGCAGGTAAGTTCTAGCA }\end{array}$ \\
\hline SK604 & JX503287 & $(\mathrm{CAT})_{11}$ & 55 & $\mathrm{P}$ & $\begin{array}{l}\text { F:CACTACTGTTGCTTGGTTATAC } \\
\text { R:TCCTCTGAGTGAAAACTGAT }\end{array}$ \\
\hline SK605 & JX503286 & $(\mathrm{GT})_{31}$ & 58 & $\mathrm{P}$ & $\begin{array}{l}\text { F:TTGACAGTCAGATAGACAGCTC } \\
\text { R:GGATGTCTTAACACGTCCAT }\end{array}$ \\
\hline SK606 & JX503285 & $(\mathrm{CA})_{6} \mathrm{~N}(\mathrm{AC})_{7}$ & 55 & I & $\begin{array}{l}\text { F:GCCACTAGACTGTCAGCATC } \\
\text { R:TGATATTCCTGTTCAGACACTC }\end{array}$ \\
\hline SK610 & JX503281 & $(\mathrm{TG})_{6} \mathrm{~N}(\mathrm{TTC})_{6}$ & 58 & I & $\begin{array}{l}\text { F:TCTCATCATCACTGCTGCC } \\
\text { R:CCAGAACAGCACCTGTCAC }\end{array}$ \\
\hline SK611 & JX503280 & $(\mathrm{TGA})_{7}$ & 55 & $\mathrm{P}$ & $\begin{array}{l}\text { F:GTGGACACGACAAAACGA } \\
\text { R:AAGCAACACCGTACAACAGT }\end{array}$ \\
\hline SK612 & JX503279 & $(\mathrm{GAG})_{7} \mathrm{~N}(\mathrm{GAG})_{4}$ & 58 & I & $\begin{array}{l}\text { F:TGAAGTGTCTGAAGGAGTATGTC } \\
\text { R:CGTGATCTCCCTGGGTGT }\end{array}$ \\
\hline SK614 & JX503277 & $(\mathrm{AAG})_{5}$ & 55 & $P$ & $\begin{array}{l}\text { F:GAGCAGCAAACACTGGAGG } \\
\text { R:GTCTTTCGATGGTGGATATTCA }\end{array}$ \\
\hline SK615 & JX503276 & $(\mathrm{CAC})_{6}$ & 60 & $\mathrm{P}$ & $\begin{array}{l}\text { F:CTGCTCCTCTACATGCCAAT } \\
\text { R:CTCATCTCTGCCCTCTAGTG }\end{array}$ \\
\hline SK617 & JX503274 & $(\mathrm{GTG})_{5}$ & 58 & $\mathrm{P}$ & $\begin{array}{l}\text { F:GATCTGCTGAGGTGACTCTT } \\
\text { R:ATCAGACAGAGCAACAGAGA }\end{array}$ \\
\hline SK618 & JX503273 & $(\mathrm{AC})_{15}$ & 55 & $\mathrm{P}$ & $\begin{array}{l}\text { F:ATACCGATTTGGAGAAAGC } \\
\text { R:GTCGCCATTCTTTACTCTGT }\end{array}$ \\
\hline SK619 & JX503272 & $(\mathrm{GTG})_{4} \mathrm{~N}(\mathrm{GGT})_{6}$ & 60 & I & $\begin{array}{l}\text { F:GGTAGTGGTCAGGTTTCAGG } \\
\text { R:CTCGGTTACCACCAGCAG }\end{array}$ \\
\hline SK620 & JX503271 & $(\mathrm{ATC})_{5}$ & 58 & $\mathrm{P}$ & $\begin{array}{l}\text { F:CCTGCTGGTGGAAGAAGT } \\
\text { R:AAACCTCCCACAGACCTAGT }\end{array}$ \\
\hline SK621 & JX503270 & $(\mathrm{CA})_{21}$ & 55 & $\mathrm{P}$ & $\begin{array}{l}\text { F:TATAGGCAAACAGAGACACA } \\
\text { R:GCTGGGTAATTTCTGCAT }\end{array}$ \\
\hline SK622 & JX503269 & $(\mathrm{TG})_{16}$ & 58 & $\mathrm{P}$ & $\begin{array}{l}\text { F:TGATTCACTGATGCTTTCTC } \\
\text { R:GGTGACAAATACTGGTACGG }\end{array}$ \\
\hline SK623 & JX503268 & $(\mathrm{TGTA})_{5} \mathrm{~N}(\mathrm{CTGTA})_{3}$ & 55 & I & $\begin{array}{l}\text { F:CAGATCACATTTCCACTACAC } \\
\text { R:GGGTAGATAAAGGAGCACAG }\end{array}$ \\
\hline SK625 & JX503266 & $(\mathrm{CA})_{6} \mathrm{~N}(\mathrm{CCA})_{5}$ & 58 & I & $\begin{array}{l}\text { F:AAGTCATCACTCTGCTCATC } \\
\text { R:ACTCTGGACTCCACCTTCT }\end{array}$ \\
\hline SK626 & JX503265 & $(\mathrm{AC})_{11}$ & 60 & $\mathrm{P}$ & $\begin{array}{l}\text { F:CCTATTTCCTTCCCTCACTT } \\
\text { R:CACTCGTGACTCAGCTCAGA }\end{array}$ \\
\hline SK627 & JX503264 & $(\mathrm{TG})_{21}$ & 55 & $\mathrm{P}$ & $\begin{array}{l}\text { F:AATGCTTCAATGTGTGCTCA } \\
\text { R:CAGAGGAGGCACTGTCACTA }\end{array}$ \\
\hline
\end{tabular}




\begin{tabular}{|c|c|c|c|c|c|}
\hline Locus name & GenBank accession & Repeat motif & $\mathrm{Ta}\left({ }^{\circ} \mathrm{C}\right)$ & Locus type & Primer sequence $\left(5^{\prime}-3^{\prime}\right)$ \\
\hline \multicolumn{6}{|c|}{ Transcriptome-derived SSR } \\
\hline SK628 & JX503263 & $(\mathrm{CT})_{8} \mathrm{~N}(\mathrm{TC})_{15}$ & 55 & I & $\begin{array}{l}\text { F:GCTGCATACTCTACGTCTCC } \\
\text { R:CTGCCAAATCTAATCACACT }\end{array}$ \\
\hline SK629 & JX503262 & $(\mathrm{AGAC})_{3}$ & 55 & $\mathrm{P}$ & $\begin{array}{l}\text { F:TCCCTGACGGTGTGTGGT } \\
\text { R:GGTTCGATACGACAGGAAGAC }\end{array}$ \\
\hline SK630 & JX503261 & $(\mathrm{AC})_{15}$ & 55 & $\mathrm{P}$ & $\begin{array}{l}\text { F:ATAGGCTGAGACATCCGT } \\
\text { R:ATGGACCTCTTTAGAAGTACA }\end{array}$ \\
\hline SK631 & JX503260 & $(\mathrm{AC})_{6} \mathrm{~N}(\mathrm{AC})_{23}$ & 58 & I & $\begin{array}{l}\text { F:AGACGAGCACTTTGGACCAC } \\
\text { R:TCCGAAGCAGTCATTTTACAG }\end{array}$ \\
\hline SK632 & JX503259 & $(\mathrm{GAT})_{8}$ & 58 & $P$ & $\begin{array}{l}\text { F:CAGAGCAAGAGGCACGTACA } \\
\text { R:GCTCGTTCCTGCTTCTCCTT }\end{array}$ \\
\hline SK633 & JX503258 & $(\mathrm{TGG})_{5}$ & 55 & $\mathrm{P}$ & $\begin{array}{l}\text { F:TCAAGTAGAGAGTCCCAAGA } \\
\text { R:GAAGTGCCACTCTGGTCT }\end{array}$ \\
\hline SK634 & JX503257 & $(\mathrm{TCC})_{6}$ & 60 & $P$ & $\begin{array}{l}\text { F:TGCCACCTCGCTCTTGTCCA } \\
\text { R:AGGGAGGCGGAGGGAGCATA }\end{array}$ \\
\hline SK635 & JX503256 & $(\mathrm{GAA})_{5}$ & 60 & $P$ & $\begin{array}{l}\text { F:TGTTTGCCAGAATGGTAATC } \\
\text { R:TCTAGTGTGGTTTGTGGATCG }\end{array}$ \\
\hline SK636 & JX503255 & $(\mathrm{GGA})_{5}$ & 55 & $P$ & $\begin{array}{l}\mathrm{F}: \text { CAATTTGCATCATGGTGTAG } \\
\text { R:AGCAAACAAACACATCTCTC }\end{array}$ \\
\hline SK637 & JX503254 & $(\mathrm{CAG})_{5}$ & 55 & $\mathrm{P}$ & $\begin{array}{l}\text { F:CCAGATAAGGTGAACCAGA } \\
\text { R:GGCAAATAAGAAGTCACTCC }\end{array}$ \\
\hline SK638 & JX503253 & $(\mathrm{AG})_{9}$ & 55 & $P$ & $\begin{array}{l}\text { F:TCTCCAGCATTGAGTCAGAC } \\
\text { R:GACTTCACCACAGCTTAGCC }\end{array}$ \\
\hline SK639 & JX503252 & $(\mathrm{GTG})_{5}$ & 60 & $P$ & $\begin{array}{l}\text { F:GAGGAAGGGTAGCGAGTGTA } \\
\text { R:GAAACTGTCAGCCTCAGAAC }\end{array}$ \\
\hline Genomic SSR & & & & & \\
\hline FC055 & JX449062 & $(\mathrm{TG})_{8}(\mathrm{GT})_{14}(\mathrm{GT})_{5} \mathrm{~N}(\mathrm{TG})_{14}$ & 55 & I & $\begin{array}{l}\mathrm{F}: A T C A A T G T G T T T T G C C T G A A \\
\text { R:AGAGACTGTGATTGGATTTG }\end{array}$ \\
\hline FC056 & JX449063 & $(\mathrm{CCT})_{10}$ & 55 & $P$ & $\begin{array}{l}\text { F:ACACACAAGACCGACTGAAT } \\
\text { R:AACAGACTTTCCATTCAGGT }\end{array}$ \\
\hline FC057 & JX449064 & $(\mathrm{GA})_{7} \mathrm{~N}(\mathrm{GT})_{12}$ & 58 & I & $\begin{array}{l}\text { F:ACGGGAAGAGAATCAACTAC } \\
\text { R:CTGTCTTGTTTTCCATTCCC }\end{array}$ \\
\hline FC059 & JX449066 & $(\mathrm{TCC})_{9}$ & 62 & $P$ & $\begin{array}{l}\mathrm{F}: G G A G G A T G A G G A T G A G G A T G \\
\text { R:CGGTTGACCTTCATTCGGAC }\end{array}$ \\
\hline FC060 & JX449067 & $(\mathrm{CCT})_{8}$ & 60 & $\mathrm{P}$ & $\begin{array}{l}\text { F:GTTACAAGGAACTGGGGACC } \\
\text { R:CTTTGTTTCCAGATGAAGGG }\end{array}$ \\
\hline FC061 & JX449068 & $(\mathrm{AC})_{6} \mathrm{~N}(\mathrm{GT})_{9} \mathrm{~N}(\mathrm{CA})_{7}$ & 55 & I & $\begin{array}{l}\text { F:TCCAGTGTTTTTGAATGAAG } \\
\text { R:ACTCGTGGTTGCCTCTGA }\end{array}$ \\
\hline FC062 & JX449069 & $(\mathrm{CTC})_{10}$ & 62 & $\mathrm{P}$ & $\begin{array}{l}\text { F:CTGAGTAACGCCTTCGCTGT } \\
\text { R:CGTGCCACCTGCTGTCTGT }\end{array}$ \\
\hline FC063 & JX449071 & $(\mathrm{GGA})_{7}$ & 60 & $\mathrm{P}$ & $\begin{array}{l}\text { F:TGAGAGGAGTAGGAGGGTGT } \\
\text { R:GTCAACTAAGGATAGGCTAC }\end{array}$ \\
\hline FC064 & JX449072 & $(\mathrm{GAG})_{6}$ & 60 & $\mathrm{P}$ & $\begin{array}{l}\text { F:AAGGGCTGTGGGGATTGTAG } \\
\text { R:GCCACCGACAAATCTGATGA }\end{array}$ \\
\hline FC066 & JX449073 & $(\mathrm{GT})_{10} \mathrm{~N}(\mathrm{TG})_{5} \mathrm{~N}(\mathrm{TG})_{5}$ & 58 & I & $\begin{array}{l}\mathrm{F}: \text { CTTCCAGGAGTGCTGACTAA } \\
\text { R:TCACCCACTCTCTGTTATGT }\end{array}$ \\
\hline FC068 & JX449074 & $(\mathrm{TG})_{7} \mathrm{~N}(\mathrm{TG})_{13} \mathrm{~N}(\mathrm{TG})_{12} \mathrm{~N}(\mathrm{TG})_{17} \mathrm{~N}(\mathrm{GT})_{11}$ & 62 & I & $\begin{array}{l}\text { F:CACCCATTCCCGTCTCTCTT } \\
\text { R:GTGTTTTCCGCTCCGTCCTT }\end{array}$ \\
\hline FC069 & JX449075 & $(\mathrm{TG})_{8} \mathrm{~N}(\mathrm{GT})_{14} \mathrm{~N}(\mathrm{TG})_{14} \mathrm{~N}(\mathrm{CTC})_{9}$ & 60 & I & $\begin{array}{l}\text { F:GTGTTGAAGGTGTGGAGGTG } \\
\text { R:TGCTCTGATGATGGTCGTTA }\end{array}$ \\
\hline FC071 & JX449077 & $(\mathrm{TG})_{9} \mathrm{~N}(\mathrm{TG})_{14} \mathrm{~N}(\mathrm{TG})_{7}$ & 55 & I & $\begin{array}{l}\text { F:ATCCTGAATAGGGCTGCTAC } \\
\text { R:TAAAGAAATGGAGCAAAGTTAT }\end{array}$ \\
\hline FC072 & JX449078 & $(\mathrm{GT})_{24}$ & 55 & $\mathrm{P}$ & $\begin{array}{l}\text { F:AATAGTAGTGGGGTCTGGGA } \\
\text { R:ATCCATTGTATCTCATTGTC }\end{array}$ \\
\hline FC073 & JX449079 & $(\mathrm{GAG})_{7} \mathrm{~N}(\mathrm{GAGGAT})_{3}$ & 52 & I & $\begin{array}{l}\text { F:TCATCTAAAAGGCAGTCT } \\
\text { R:CTCTGCGATGCCATAAAG }\end{array}$ \\
\hline FC074 & JX449080 & $(\mathrm{TCC})_{7}$ & 55 & $\mathrm{P}$ & $\begin{array}{l}\text { F:GCAGAATAGTTTGTATGTCA } \\
\text { R:AAGAGTTTCAGGGTTTGAGA }\end{array}$ \\
\hline FC075 & JX449081 & $(\mathrm{CCT})_{6}$ & 58 & $P$ & $\begin{array}{l}\text { F:ACATCAACATTAGAGACCCA } \\
\text { R:CTGACTTTCTGCTCCAGGTT }\end{array}$ \\
\hline FC078 & JX449084 & $(\mathrm{TCC})_{5} \mathrm{~N}(\mathrm{TCC})_{4}$ & 55 & I & $\begin{array}{l}\text { F:AGTAATGTTGTGGAAGTTTG } \\
\text { R:AACCACCTGCCTTAGCAAGT }\end{array}$ \\
\hline
\end{tabular}

Continued on next page 


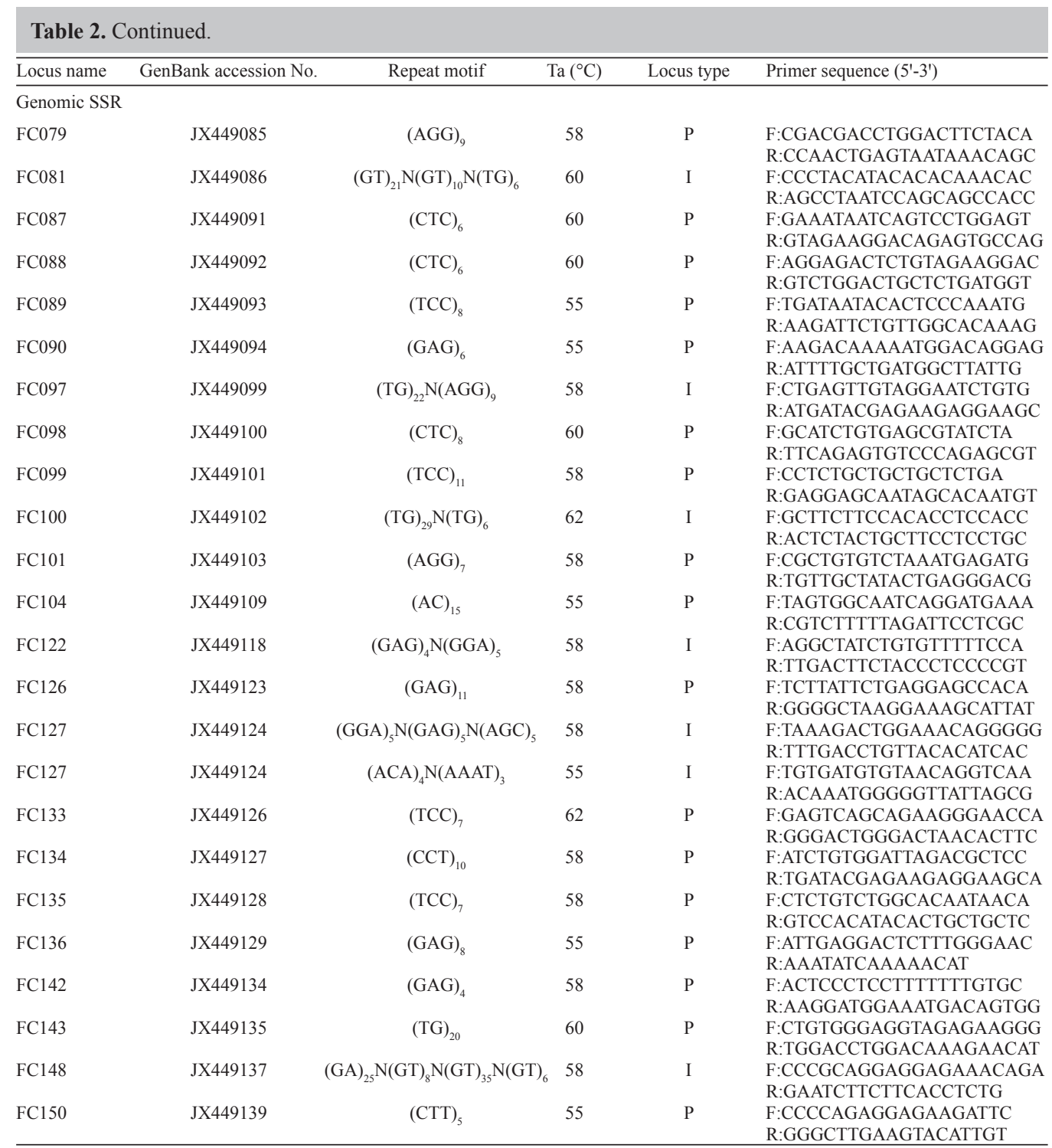

$\mathrm{P}=$ pure; $\mathrm{I}=$ interrupted; $\mathrm{C}=$ compound.

\section{DISCUSSION AND CONCLUSIONS}

These loci departure from HWE might have been caused by the recent dramatic decline in spawning populations, and consequent non-random mating and genetic bottlenecks (Zhang and Zhao, 1999). The genomic SSRs of many aquatic species show generally more polymorphism compared to transcriptome-derived SSRs (Zhan et al., 2009; Li et al., 2010). In contrast, in this study, transcriptome-derived SSRs displayed a greater mean PIC value (0.638) compared to genomic SSRs (0.477) among the individuals sampled. One possible explanation 
for this difference is that tri-nucleotide repeats were the most abundant (63\%) in genomic SSRs, whereas di-nucleotide repeats were the most abundant (72\%) in EST-SSR. SSR markers with di-nucleotide repeats generally had higher polymorphism compared to those with tri-nucleotide repeats (Blair et al., 1999; Celton et al., 2009). Because we only used a small sample size from each population, it was difficult to obtain accurate data about genetic difference or genetic structure among populations. SSR markers have been extensively used to evaluate the genetic diversity and structure of farmed food fish species, such as salmon (Norris et al., 1999), rainbow trout (Thrower et al., 2004), and tilapia (Rutten et al., 2004). However, relevant reports about Siniperca species remain limited (Wang et al., 2006; Yang et al., 2010), particularly for $S$. kneri. Therefore, we intend to focus future research on $S$. kneri in these areas.

The 55 loci (37 transcriptome-derived SSRs and 18 genomic SSRs) developed and characterized by this study for $S$. kneri are the first on record. The transcriptome data provide an excellent source for the mining and development of SSR markers. Moreover, the transcriptome-derived SSRs directly reflect the variation in gene transcriptional regions, which are closely associated with phenotypic, physiological, and biochemical indices, as well as with metabolic features (Song et al., 2012). Furthermore, utilization of the SSR markers developed from various sources may be more precise and objective for the construction of genetic linkage maps, QTL analysis of phenotypic traits, high-throughput genotyping of marker-assisted selection, and association genetics.

\section{ACKNOWLEDGMENTS}

Research supported by the National Natural Science Foundation of China (\#31172420), the National Basic Research Program of China (\#2009CB118702), the Fundamental Research Funds for the Central Universities (\#2010PY010, \#2011PY030), and the Huazhong Agricultural University Scientific \& Technological Self-innovation Foundation (\#2012SC24).

\section{REFERENCES}

Billotte N, Lagoda PJL, Risterucci AM and Baurens FC (1999). Microsatellite-enriched libraries: applied methodology for the development of SSR markers in tropical crops. Fruits 54: 277-288.

Blair MW, Panaud O and McCouch SR (1999). Inter-simple sequence repeat (ISSR) amplification for analysis of microsatellite motif frequency and fingerprinting in rice (Oryza sativa L.). TAG Theor. Appl. Genet. 98: 780-792.

Botstein D, White RL, Skolnick M and Davis RW (1980). Construction of a genetic linkage map in man using restriction fragment length polymorphisms. Am. J. Hum. Genet. 32: 314-331.

Bouck A and Vision T (2007). The molecular ecologist's guide to expressed sequence tags. Mol. Ecol. 16: 907-924.

Celton JM, Tustin DS, Chagne D and Gardiner SE (2009). Construction of a dense genetic linkage map for apple rootstocks using SSRs developed from Malus ESTs and Pyrus genomic sequences. Tree Genet. Genomes 5: 93-107.

Hansen MM, Kenchington E and Nielsen EE (2001a). Assigning individual fish to populations using microsatellite DNA markers. Fish Fish. 2: 93-112.

Hansen MM, Ruzzante DE, Nielsen EE and Mensberg KLD (2001b). Brown trout (Salmo trutta) stocking impact assessment using microsatellite DNA markers. Ecol. Appl. 11: 148-160.

He S, Liang XF, Sun J, Li L, et al. (2013). Insights into food preference in hybrid F1 of Siniperca chuatsi (†) x Siniperca scherzeri $(\stackrel{\Im}{)})$ mandarin fish through transcriptome analysis. BMC Genomics 14: 601.

Holm S (1979). A simple sequentially rejective multiple test procedure. Scand. J. Stat. 6: 65-70.

Kuang G, Lu S, Zheng S and Wu Q (2009). Isolation and evaluation of 18 microsatellite markers in Siniperca chuatsi (Basilewsky). Mol. Ecol. Resour. 9: 1473-1475. 
Li Q and Wan JM (2005). SSRHunter: development of a local searching software for SSR sites. Yi Chuan 27: 808-810.

Li Q, Shu J, Zhao C, Liu S, et al. (2010). Characterization of genic microsatellite markers derived from expressed sequence tags in Pacific abalone (Haliotis discus hannai). Chin. J. Ocean. Limnol. 28: 46-54.

Liang XF (1996). Study on Mandarin fish and its culture home and abroad. Sci. Tech. Inf. 23: 13-17.

Liu X, Luo W, Zeng C, Wang W, et al. (2011). Isolation of new 40 microsatellite markers in Mandarin fish (Siniperca chuatsi). Int. J. Mol. Sci. 12: 4180-4189.

Norris AT, Bradley DG and Cunningham EP (1999). Microsatellite genetic variation between and within farmed and wild Atlantic salmon (Salmo salar) populations. Aquaculture 180: 247-264.

Perez RE, Takagi M and Taniguchi N (1999). Genetic variability and pedigree tracing of a hatchery-reared stock of red sea bream (Pagrus major) used for stock enhancement, based on microsatellite DNA markers. Aquaculture 173: 413-423.

Qu C, Liang X, Huang W and Cao L (2012). Isolation and characterization of 46 novel polymorphic EST-simple sequence repeats (SSR) markers in two sinipercine fishes (Siniperca) and cross-species amplification. Int. J. Mol. Sci. 13: 9534-9544.

Raymond $\mathrm{M}$ and Rousset F (1995). GENEPOP (version 1.2): population genetics software for exact tests and ecumenicism. J. Hered. 86: 248-249.

Rutten MJ, Komen H, Deerenberg RM, Siwek M, et al. (2004). Genetic characterization of four strains of Nile tilapia (Oreochromis niloticus L.) using microsatellite markers. Anim. Genet. 35: 93-97.

Song YP, Jiang XB, Zhang M, Wang ZL, et al. (2012). Differences of EST-SSR and genomic-SSR markers in assessing genetic diversity in poplar. Forest. Stud. China 14: 1-7.

Thrower F, Guthrie C III, Nielsen J and Joyce J (2004). A comparison of genetic variation between an anadromous steelhead, Oncorhynchus mykiss, population and seven derived populations sequestered in freshwater for 70 years. Environ. Biol. Fish. 69: 111-125.

Van Oosterhout C, Hutchinson WF, Wills DPM and Shipley P (2004). Micro-Checker: software for identifying and correcting genotyping errors in microsatellite data. Mol. Ecol. Notes 4: 535-538.

Wang WW, Zhao JL and Li SF (2006). Genetic variation of the mitochondrial DNA control region among 5 populations of Siniperca scherzeri Steindachner in China. J. Shanghai Fish. Univ. 4: 398-402.

Weber JL (1990). Informativeness of human (dC-dA)n.(dG-dT)n polymorphisms. Genomics 7: 524-530.

Yang M, Liang XF, Tian CX, Gul Y, et al. (2012). Isolation and characterization of fifteen novel microsatellite loci in golden mandarin fish (Siniperca scherzeri) Steindachne. Conservat. Genet. Resour. 4: 599-601.

Yang Y, Liang X, Lin Q, Li J, et al. (2010). Cultivated and natural populations of Siniperca chuatsi in Guangdong and Jiangxi: sequence polymorphism of the mitochondrial DNA control region and population genetic diversity analysis. J. Fish. China 4: 515-520.

Yeh FC and Boyle TJB (1997). Population genetic analysis of codominant and dominant markers and quantitative traits. Belg. J. Bot. 129: 157.

You FM, Huo N, Gu YQ, Luo MC, et al. (2008). BatchPrimer3: a high throughput web application for PCR and sequencing primer design. BMC Bioinformatics 9: 253.

Zhan A, Wang Y, Brown B and Wang HP (2009). Isolation and characterization of novel microsatellite markers for yellow perch (Perca flavescens). Int. J. Mol. Sci. 10: 18-27.

Zhang CG and Zhao YH (1999). The resource status of Siniperca chuatsi in China and methods for its recover. Bull. Biol. 34: 9-11.

Zhou CW, Yang Q and Cai DL (1988). On the classification and distribution of the Sinipercinae fishes (family Serranidae). Zool. Res. 9: 113-125. 